\title{
Safer staining method for acid fast bacilli
}

\author{
R C Ellis, L A Zabrowarny
}

\begin{abstract}
To develop a method for staining acid fast bacilli which excluded highly toxic phenol from the staining solution. A lipophilic agent, a liquid organic detergent, LOC High Studs, distributed by Amway, was substituted.

The acid fast bacilli stained red; nuclei, cytoplasm, and cytoplasmic elements stained blue on a clear background. These results compare very favourably with acid fast bacilli stained by the traditional method.

Detergents are efficient lipophilic agents and safer to handle than phenol. The method described here stains acid fast bacilli as efficiently as traditional carbol fuchsin methods. LOC High Suds is considerably cheaper than phenol.
\end{abstract}

(F Clin Pathol 1993;46:559-560)

The stained appearance of acid fast bacilli was first described in 1882 by Koch, who used alkaline methylene blue to demonstrate the organism. ${ }^{1}$ The method known as ZiehlNeelsen was originally developed in 1882 by Ehrlich, who described the acid fast properties of the organism. ${ }^{2} \mathrm{He}$ was unable to remove the stain from mycobacteria with dilute acids after staining with a fuchsin-aniline oil mixture. Modifications to that method were made by Ziehl in 1882 and 1883, who first used basic fuchsin with carbolic acid (phenol $\left.\mathrm{C}^{6} \mathrm{H}^{5} \mathrm{OH}\right){ }^{34}$ In 1883 Neelsen used the same staining solution as Ziehl but destained tissue elements with $25 \%$ sulphuric acid. ${ }^{5}$ Substitutes for basic fuchasin in the original method have included such dyes as Night blue, Victoria Blue $R$, triphenyl and diphenyl naphthylamine dyes with pararosaniline and rosaniline, and new fuchsin. Fluorescence methods have been recommended using Auramine $\mathrm{O}^{8}$ as a fluorochrome. In more recent years immunopathological methods have been developed using monoclonal antibodies, ${ }^{6}$ and mycobacteria have been detected using the polymerase chain reaction. ${ }^{7}$ Despite the development of alternative methods for the demonstration of mycobacteria, the ZiehlNeelsen stain is commonly requested to demonstrate their presence.

Mycobacterial cell walls contain complex lipids composed of $\beta$-hydroxy carboxylic acids (mycolic acids) with chain lengths of up to 90 carbon atoms $^{8}$ and long chain length phthiocerols and polymethyl branched fatty acids. Both $\alpha$ and hydroxy mycolic acids have been isolated from mycobacteria. ${ }^{9}$ Other complex lipids and glycolipids have also been isolated.

The property of acid fastness is related to the carbon chain length of the mycolic acid. ${ }^{8}$ The mycolic acid (and other cell wall lipids) present an initial barrier to dye entry as well as elution. In the original Ziehl-Neelsen method this is partly overcome by adding phenol, a lipophilic agent, to a concentrated aqueous solution of basic fuchsin, and partly by heating and extending the staining time.

Phenol is said to increase lipophilia and thus aid passage of the dye through the protective lipid wall, ${ }^{8}$ enabling the dye to bind with negatively charged ions present in the bacterial structure. After staining, the lipid coating is reconstituted by removing the lipophilic agent. Subsequent differentiation in acid/alcohol solutions removes the dye from all tissue structures but leaves dye in the organism, the lipid wall now acting as a barrier to the removal of the dye. Because of the hazardous nature of phenol with the inherent danger to staff who handle the concentrated solution, alternative lipophilic agents were investigated for suitability in the staining of acid fast bacilli (material safety data sheet for phenol, Ajax chemicals).

\section{Methods}

REAGENTS

1 Staining solution-Solution A: basic fuchsin (CI 42500) (1 g); absolute ethyl alcohol (10 ml).

Solution B: LOC High Suds (Amway) $(0.6 \mathrm{ml})$; distilled water $(100 \mathrm{ml})$.

The two solutions can be kept as stock solutions and mixed immediately before use. The combined staining solution keeps well and can be used repeatedly for staining. To date we have had a staining solution in continuous use for six months.

$23 \%$ hydrochloric acid in 95\% ethyl alcoholAbsolute ethyl alcohol (95 ml); distilled water (2 $\mathrm{ml})$; concentrated hydrochloric acid (3 ml). Make up the alcohol solution then add the concentrated acid.

$30 \cdot 25 \%$ methylene blue-Methylene blue $(0.25 \mathrm{~g})$; glacial acetic acid $(1 \mathrm{ml})$; distilled water $(99 \mathrm{ml})$.

All tissue was fixed in $10 \%$ neutral buffered formalin.

Sections were routinely cut at $3 \mu \mathrm{m}$ from tissue embedded in paraffin wax.

\author{
Correspondence to: \\ Dr R C Ellis \\ Histopathology, The \\ South Australia 5097, \\ Australia
}


Mouse skin, infected with Mycobacterium tuberculosis, was used as control material during the development of the method.

\section{METHOD}

1 Place the staining solution in a Coplin jar and preheat to $60^{\circ} \mathrm{C}$ for 10 minutes.

2 Dewax sections in xylene, rinse briefly in graded alcohols, bring to water and stain in the preheated staining solution for $15 \mathrm{~min}$ utes.

3 Place the Coplin jar containing the slides into running cold tap water for 2 minutes before removing the slides from the Coplin jar.

4 Remove the slides from the Coplin jar and wash in running water for 1 minute.

5 Differentiate in 3\% hydrochloric acid in 95\% ethyl alcohol until no more colour runs from the slide. It is important to remove all of the basic fuchsin as residual stain in the tissue will affect the background staining with methylene blue.

6 Wash briefly in water to remove the acid alcohol.

7 Counterstain with $0.25 \%$ methylene blue in $1 \%$ acetic acid for 15 to 30 seconds.

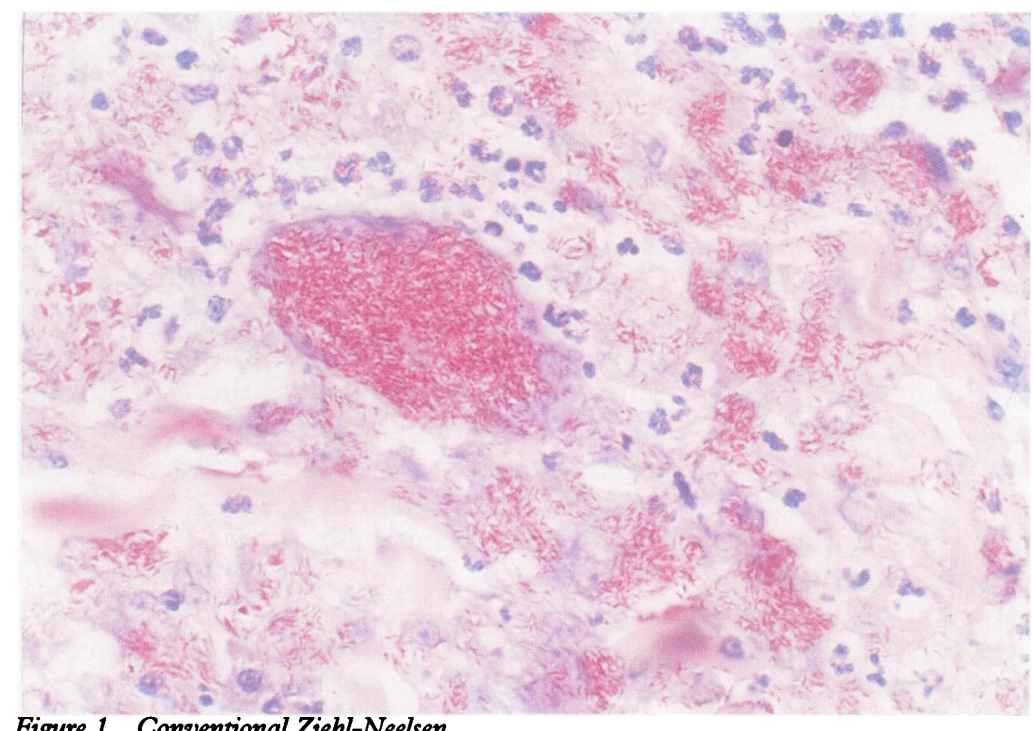

Figure 1 Conventional Ziehl-Neelsen.

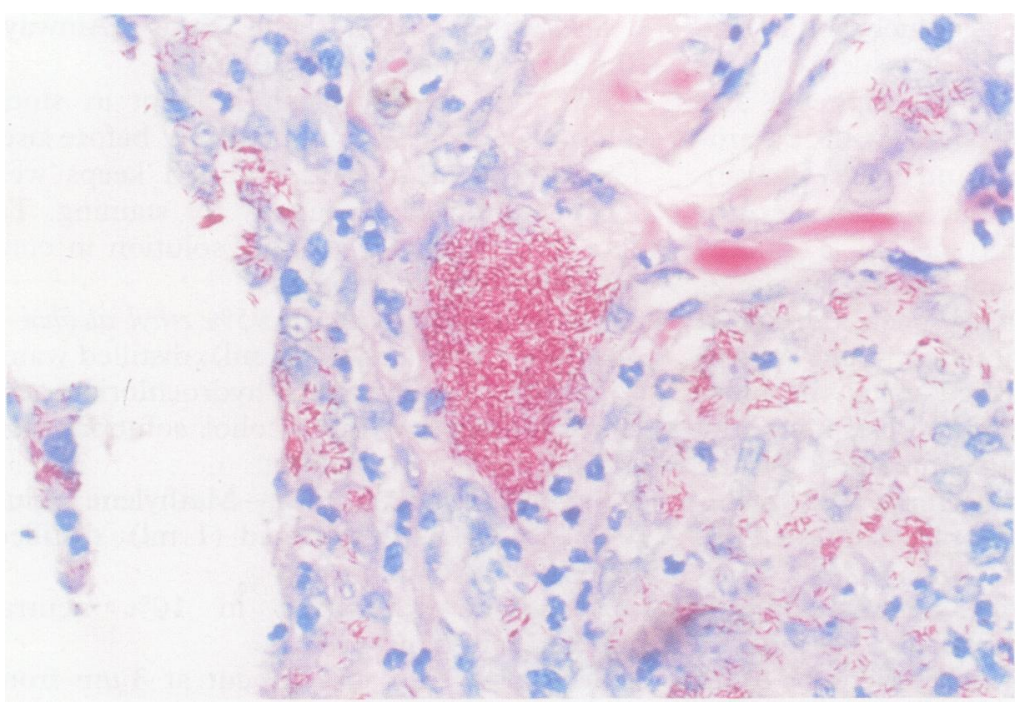

Figure 2 LOC basic fuchsin. Acid fast bacilli are just as clearly demonstrated as in figure 1 .
8 Wash in water, dehydrate in alcohols, clear in xylene and mount in DPX or other suitable neutral mounting medium.

\section{Result}

Acid fast bacilli stained red; nuclei stained blue; other tissue constituents stained blue.

The modified basic fuchsin solution stained acid fast bacilli with a similar intensity of colour to that of the traditional ZiehlNeelsen (Z-N) method. The background staining is often clearer than with a ZiehlNeelsen stain, allowing the organisms to be identified more readily.

Two slides, one stained by Ziehl-Neelsen and one stained by this method, were submitted to pathologists along with two control slides stained by each method. Four senior pathologists examined the slides. Nineteen requests for staining for acid fast bacilli have been received over the past six months. One case proved positive. Four positive cases from our archives were recovered and stained with the new method. Control sections from three other medical laboratories in the Adelaide metropolitan area were also obtained. Where acid fast organisms were detectable they were present in both test slides. The pathologists could not distinguish the conventional carbol fuchsin stain (fig 1) from the LOC fuchsin stain (fig 2).

\section{Discussion}

Detergents are efficient lipophilic agents and apart from causing severe irritation, if splashed inadvertently into an eye, are quite safe to handle. This modified basic fuchsin staining solution stains acid fast organisms with a similar intensity to the traditional method of Ziehl-Neelsen. Because the staining solution does not contain phenol, it is safer to prepare and handle.

We thank the histology staff who performed the "extra" staining, Dr P W Allen, and Dr L McCormac for their critical appraisal of the manuscript, and Dr PW Allen, RB Dymock, appraisal of the manuscript, and Dr PW Allen, RB Dym
J Pierides and R Barua, who evaluated the stained slides.

1 Koch R. Die Ätiologie der Tuberckulose. Berl Klin Wochenschr 1882;19:221.

2 Ehrlich P. Referate aus den Verein für innere Medicin zu Berlin. Deutsche Med Wochenschr 1882;8:269.

3 Ziehl F. Zur Farbung des Tuberkelbacillus. Deutsche Med Wochenschr 1882;8:451.

$4 \mathrm{Ziehl}$ F. Ueber die Färbung des Tuberkelbacillus. Deutsche Med Wochenschr 1883;9:247-9.

5 Neelsen F. Ein Casuistischer Beitrag zur Lehre von der Tuberkulose. Zentralblatt für die medizinischen Wissenschafen 1883:21:497-501.

6 Barbolini G, Bisetti A, Colizzi V, Damiani G, Migaldi M, Vismara D. Immunohistologic analysis of mycobacterial Vismara $D$. Immunohistologic analysis of mycobacterial
antigens by monoclonal antibodies in tuberculosis and antigens by monoclonal antibodies in tuberculosi

Eisenach K, Sifford M, Cave M, Bates J, Crawford J.

Eisenach K, Sifford M, Cave M, Bates J, Crawford J.
Detection of mycobacterium tuberculosis in sputum Detection of mycobacterium tuberculosis in sputum Respir Dis 1991;144:1160-3.

8 Prento P, Barer MR, Lyon $H$, Hasselager E. Staining of macromolecules on the basis of charge. In: Lyon $H$, ed. Theory and strategy in histochemistry. Heidelberg: Springer Verlag, 1991:97-8.

9 Baba T, Kaneda K, Kusonose E, Kusonose M, Yano I. Molecular species of mycolic acid subclasses in eight strains of Mycobacterium smegmatis. Lipids 1988, 23:1132-8. 